positions, from 25 per cent in 1967 to 46 per cent in 1969. (The NRC survey, conducted at almost the same time, found that only 34 per cent of physicists receiving their PhDs in 1969 took up post-doctoral jobs, a discrepancy that Dr Koch attributes to the NRC data bcing less up to date.) But the post-doctoral "holding pattern" is now dangerously extended, Dr Koch said. The AIP survey sent to chairmen of physics departments in March this year shows that they intend to reduce postdoctoral appointments in 1970-71 by an average of 21 per cent compared with 1969-70, whilst the fifteen largest institutions plan to make 41 per cent fewer appointments (see Table 1). This policy seems likely to affect foreigners in particular.

Table 1. SUMMARY OF NEW APPOINTMENTS PLANNED BY CHATRMEN OF PHYSICS DEPARTMENTS (AS OF MARCH 1970 ) FOR $1970-71$ COMPARED WITH 1969-70

$$
\begin{array}{cc}
134 & 15 \text { largest } \\
\text { institutions institutions } \\
\text { (por cent) }
\end{array}
$$

\begin{tabular}{|c|c|c|}
\hline Totals & Down 17 & Down 30 \\
\hline Teaching assistants & Down 14 & Down 33 \\
\hline Research assistants & Down 8 & Down 31 \\
\hline Unsupported & Down 27 & Down 29 \\
\hline \multicolumn{3}{|c|}{ Postdoctoral appointments } \\
\hline Totals & Down 21 & Do \\
\hline Agency funded & Down 20 & Down 58 \\
\hline Foreign nationals & Down 50 & Down 46 \\
\hline
\end{tabular}

(1) Graduate students

Conservative planning has also extended to graduate intake, which is set for a 17 per cent overall decrease with respect to last year, and a 30 per cent decrease in the thirty largest institutions. These abrupt changes, Dr Koch observed, have been brought about by a comparatively small percentage reduction in federal funds because the production of $\mathrm{PhDs}$ still in the pipeline is increasing at the rate of 8 per cent of a year and inasfar as most physicists receive their funds from federal government, an equivalent expansion of government support is required simply to employ each year's new crop of PhDs.

The potential seriousness of this situation for the country was spelt most clearly by Dr Wallace Brode, a former president of the American Chemical Society, who pointed out that the downturn in the American birth rate which oceured nine years ago will begin to be reflected in the university enrolments in the midcighties. Although in absolute terms the numbers of scientists and engineers turned out by American universities has been constantly increasing, the number as a percentage of the age group has in fact been stabilized at about 4 per cent, despite strenuous efforts to raise it, suggesting that there exists an upper limit to the proportion of students in the population who can be turned into scientists. Dr Brode's thesis is that despite the present surplus of scientists and engineers--which he estimates will "probably be less than 10 per cent of the total scientific and engineering manpower and ... will not last for more than ten years" - the general trend in demand must be upwards as society becomes more technological. With the decrease in college enrolment in the mid-1980s the demand for scientists and engineers will exceed the supply and the United States will never again be in surplus. It is all the more necessary to conserve the surplus of the fat years ahead for the lean years that lie beyond, even to the extent of creating artificial employment for scientists which, in Dr Brode's prescription, seemed reminiscent of the Works Progress Administration of the 1930s: "A 'holding pattern' to preserve an excess of technologists for this nation is an obvious necessity. ... We should establish . . technical programs in such areas as health, environmental control, pollution eradication, education and basic research, so as to retain trained scientists and engineers and expand their capability."

Dr Brode's prophecy of lean years ahead has not passed unnoticed in the Administration; Dr York, at least, admitted that he had been influenced by Brode's calculations and quoted with approval a projection by the Bureau of Labor Statistics to the effect that there will be a significant shortage of chemists and physicists as early as 1980 , although the national requirement for engineers, geophysicists and one or two other categories will be almost in balance at that time and there will be a surplus of mathematicians and life scientists. Whatever the validity of such predictions, Dr York said, it is clear that budgetary actions taken now will affect the supply of scientific manpower at the end of the decade when, "according to the predictions of all of the federal agencies, there will be a substantial shortage of physical scientists and engineers. The position which we have taken at OST during the formation of the 1972 budget is that the level of 1971 should be maintained at constant value until a better understanding and a more sophisticated analysis of the country's manpower needs has been made."

\section{Good Time to be a Geophysicist}

IN contrast to the situation in physics, the employment situation in most disciplines of the earth sciences is reasonably cheerful both now and in the foreseeable future. About 3,500 geoscientists in the United States and Canada are expected to receive their undergraduate or graduate degrees in 1970-71 and although only 2,500 professional positions (exclusive of teaching) have been identified by the American Geological Institute for 1971 there are good prospects for the remaining 1,000 in teaching. In a "Message to Students" in this month's Geotimes, Dr Linn Hoover, executive director of the AGI, says the overall employment picture for earth scientists is not bleak although at present "Geophysicists, geochemists and earth science teachers have better employment prospects than geologists, oceanographers and paleontologists. ... Geophysicists are in great demand at all degree levels whereas geologists, especially those with a BS degree only, may find severe competition for jobs".

In a five year prospective survey conducted in February last year the AGI estimated the total employment of earth scientists would rise by 4 per cent to 32,900 by the end of 1974 . Total academic employment would grow by 39 per cent over the same period at the rate of about 750 new faculty members a year. A new AGI survey now under way though not yet completed seems to confirm these predictions. 